\title{
МЕТОДЫ УПРАВЛЕНИЯ ПОЗНАВАТЕЛЬНОЙ ДЕЯТЕЛЬНОСТЬЮ И ПОНИМАНИЕМ МЛАДШИХ ШКОЛЬНИКОВ
}

\section{METHODS OF MANAGEMENT OF COGNITIVE ACTIVITIES AND UNDERSTANDING OF YOUNGER SCHOOLCHILDREN}

\section{O. Shadurko}

Summary: The article discusses the methods of managing cognitive activity and understanding of younger students. The federal educational standard of elementary general education considers the development of cognitive activity as a target landmark that ensures the successful educational activity of a primary school student. Creating conditions for the development of cognitive activity and understanding in primary school children and its activation is one of the urgent tasks of an elementary education teacher. The youngest student by the time of transition to the secondary level of education should have a developed, stable and diverse system of interests, which is an indicator formed by a growing personality. The author concludes that the combined lesson "does not focus" the very idea of an activity-based approach to the organization of training. For the successful activation of cognitive activity, it is necessary in the learning process to create conditions for enhancing cognitive activity, as well as to improve the system of mastering basic knowledge, skills, and it is necessary to observe the conditions for activating cognitive activity: an atmosphere of goodwill and cooperation in the classroom; a "success" situation for each student; inclusion of each student in collective work; the use of non-standard tasks when learning new things or when repeating already completed material; taking into account the individual characteristics of students.

Keywords: cognitive activity, understanding, primary school age, teaching methods, activity approach.

\author{
Шадурко Олег Владимирович \\ Соискатель, Московский педагогический \\ государственный университет \\ 9911151@gmail.com
}

Аннотация: В статье рассматриваются методы управления познавательной деятельностью и пониманием младших школьников. Федеральный образовательный стандарт начального общего образования рассматривает развитие познавательной деятельности как целевой ориентир, обеспечивающий успешную учебную деятельность младшего школьника. Создание условий для развития познавательной деятельности и понимания у детей младшего школьного возраста и его активизации является одной из актуальных задач педагога начального общего образования. Младший школьник к моменту перехода на среднюю ступень образования должен иметь развитую, устойчивую и разностороннюю систему интересов, которая является показателем сформированное подрастающей личности. Автор приходит к выводу, что комбинированный урок «не фокусирует» саму идею деятельностного подхода к организации обучения. Для успешной активизации познавательной деятельности необходимо в процессе обучения создавать условия для активизации познавательной деятельности, а также совершенствовать систему усвоения базовых знаний, умений и навыков, при этом необходимо соблюдать условия активизации познавательной деятельности: атмосфера доброжелательности и сотрудничества в классе; ситуация «успеха» для каждого учащегося; включение каждого учащегося в коллективные работы; использование нестандартных заданий при изучении нового или при повторении уже пройденного материала; учет индивидуальных особенностей учащихся.

Ключевые слова: познавательная деятельность, понимание, младший школьный возраст, методы обучения, деятельностный подход.
$\Pi$ роблема развития познавательной деятельности младших школьников является одной из самых актуальных в педагогической психологии. Современное общество ставит перед детьми требование умение самостоятельно усваивать знания и грамотно использовать полученную информацию в социуме.

Многочисленные наблюдения педагогов показали, что ребенок, который не усвоил способы работы с информацией в начальной школе, обычно показывает более низкие результаты учебной деятельности в средней школе. Для полноценного умственного развития ребенка, в начальной школе должны быть созданы условия, обеспечивающие полноценное умственное развитие младшего школьника с устойчивыми познавательными интересами мыслительной деятельности, интеллектуальными качествами и творческой инициативой. Проблема развития, коррекция и совершенствование интеллектуальных способностей учащихся - является одними из важнейших компонентов образовательного процесса в психолого-педагогической практике. Справедливо считается, что главный путь его эффективного развития - рациональная организация на уровне когнитивных процессов.

С учетом различных жизненных ситуаций одна и также информация может пониматься детьми различным образом. При этом, эмоциональное состояние опережает словесную формулировку. По мнению К.М. Творек и А. Цимпиан, выбор правильного решения задачи, в 
процессе учебной деятельности, младшим школьником зависит от умения устанавливать существенные отношения. Ребенку нужно понять, какое из свойств объекта образовательной ситуации соотносится с требуемыми условиями задачи [15, с. 24]. В случае, если информация для понимания знакома обучающемуся, то он правильно отвечает на вопросы, выполняет задания, соотносит категории данных. Если же объект понимания содержит абсолютно неизвестную информацию, то новое знание включается в контекст уже имеющихся.

По мнению Лидер, Ф., Гриффитс, Т. Л., Хьюс, К. Дж., и Гудман, Н. Д. целостность, единство, интегральность это важные свойства субъекта, выступающие основой для системности всех психических качеств личности младшего школьника, часто имеющие противоречивый и трудно совместимый характер [12, с. 46].

Понимание младшего школьника в теории 3. Хорн и С. Хемлани осуществляется в определенно организованных учебных условиях. В каждой ситуации образовательного процесса могут возникать рассогласования (внутренние противоречия) между учебной задачей и возможностью ее непосредственного решения. Образовательная ситуация включает определенную степень проблемности (рассогласования). Поиск степени проблемности педагогом есть не что иное, как процесс решения [10, с. 34]. Поэтому образовательная деятельность должна быть проанализирована под углом зрения конкретных требований, которые она предъявляет к творческому потенциалу личности младшего школьника.

Психологические принципы, законы и методы применяются к разработке образовательных стратегий, анализу обучающих ситуаций, результаты и выводы применяются в области начального образования, включая когнитивные и поведенческие аспекты детей младшего школьного возраста. По словам Скиннера, «образовательная психология - это раздел психологии, который занимается преподаванием и обучением». Данный научный подход, в котором используются психологические конструкции и инструменты для понимания различных характеристик учащихся и педагогов, учебная среда и образовательная среда взаимодействуют, чтобы изменить поведение учащихся в условиях определенной образовательной задачи.

В трудах А.М. Джонстона, С.Г. Джонсона, М.Л. Ковена и Ф.С. Кейла определено, что несмотря на различные учебные ситуации, психологические элементы мышления едины, они функционируют во взаимосвязи при решении тактических и стратегических задач $[9$, с. 1]. В познавательном процессе младшего школьника, по мнению зарубежных авторов, присутствуют такие черты как прогнозирование, предвидение этапов развития и решения учебной задачи; нахождение правильного от- вета за минимальный период времени; видение и схватывание информации при одновременном внимании к деталям.

По словам Пиля, «педагогическая психология помогает педагогу понимать психологическое развитие своих учеников, диапазон и пределы их возможностей, процесс, посредством которого они учатся, и их социальные отношения [14, с. 45]. Учитель должен уметь правильно предоставлять информацию о многих факторах, которые влияют на преподавание и обучение, и предлагать проверенные идеи по улучшению инструкции образовательного процесса. Именно педагогическая психология делает учителя эффективным, предоставляет возможность владения вербальной / невербальной обратной связью с учащимися.

Педагогическая психология связана с пониманием следующим образом:

- индивидуальные психологические особенности ученика, его развитие, потребности, возможности, интерес и способности;

- среда обучения, которая включает групповую динамику, которая способствует обучению социальным взаимодействиям;

- процесс обучения, его характер и способы его эффективного развития.

Педагогическая психология - есть научное исследование поведения человека в образовательной ситуации, и связана с факторами, принципами, концепциями и методами, которые относятся к различным аспектам роста и развития учащихся. Педагогическая психология помогает организовать на уровне класса социальную платформу, где происходит обмен идеями и полезными дискуссиями между учениками и учителями. Знание психологических процессов младшего школьника и особенно его понимания фокусируется на том, чтобы создать среду в классе благоприятной, а класс будет катализатором в создании благоприятной учебной среды для обеспечения эффективного преподавания и обучения.

Зарубежные авторы обращались к проблеме использования педагогической психологии в организации благоприятной атмосферы в классе. Например, Уильямс исследовал пять ключевых компонентов для повышения мотивации школьников: ученик, учитель, содержание, метод / процесс и среда. Эти пять компонентов могут способствовать и / или препятствовать развитию познавательной деятельности младшего школьника. Педагоги могли наблюдать за собой и своим поведением, чтобы осознать новое понимание мотивации. Эймс (1990) показал, что мотивация, как результат, важен для всех учащихся в классе.

Данлоски, Роусон, Марш, Натан и Уиллингем (2013) 
исследовали простые в обучении методы, разработанные когнитивными и педагогическими психологами, которые могут помочь учащимся достичь своих учебных целей за счет понимания и обработки информации. Bojuwoye, Moletsane, Stofile, Moolla и Sylvester (2014) изучили опыт учащихся начальной и средней школы в отношении предоставления и использование вспомогательных психологических процессов для улучшения обучения. Результаты показали, что учащиеся использовали различные формы поддержки обучения со стороны своих школ, учителей и сверстников [10, с. 70]. Поддержка обучения помогает в удовлетворении академических, социальных и эмоциональных потребностей младших школьников путем устранения препятствий на пути к обучению, создание благоприятной образовательной среды, повышение успеваемости учащихся самоуважение и повышение успеваемости учащихся наиболее важно при достижении высокого уровня понимания учебной задачи. Согунро (2015) исследовал восемь факторов мотивации для школьников. Эти мотивирующие факторы: качество обучения, качество учебной программы, актуальность и прагматизм, интерактивность класса и эффективные методы управления понимание информации, прогрессивная оценка и своевременная обратная связь, самостоятельность, благоприятная учебная среда и эффективная практика консультирования педагогом. Результаты показали, что эти восемь факторов играют важную роль в устранении или усилении уровня понимания информации младших школьников и повышают их мотивацию к эффективному обучению.

На основании приведенных выше обзоров мы можем с уверенностью заключить, что использование педагогической психологии полезно для развития понимания младших школьников и создания лучшей учебной среды. Есть основания считать, что общей основой полноценности любого интеллектуального процесса является наличие трех минимальных универсальных компонентов умственных способностей:

- высокий уровень сформированности элементарных интеллектуальных операций: анализ, синтез, сравнение, выделение наиболее значимой информации и другие, выступающие как частичные элементы мышления;

- высокая активность, бескорыстие и плюралистичность мышления проявляются в производстве большого количества разных гипотез;

- высокая организованность и целеустремленность мышления, проявляющаяся в отчетливой ориентации выявления наиболее значимых явлений.

Очевидно, что все психические функции очень важны: память, внимание, воображение, но все же ведущая когнитивная функция - это понимание. Вполне вероятно, что без понимания не будет никаких других высших психических функций.
Как было определено в теории зарубежных авторов - одним из важнейших условий, основы и средств развития личности является процесс обучения. В связи с этим Л.С. Выготский сформулировал положение, согласно которому обучение и воспитание играют ведущая роль в психическом развитии ребенка, так как «обучение предшествует развитию, продвигая его дальше и вызывая в нем новый рост. В качестве достижений теории у А.Н. Леонтьева выступает представление психологического строения у деятельности, в соответствии с которым деятельность обладает следующими компонентами: мотив, потребность, цель (как предполагаемый и желаемый результат деятельности), условия для достижения цели (где условия + цель = задача), действия (основанные на операциях, которые соответствуют задачам деятельности) [2, с. 56].

Как отмечает Н.М Мякишева, у каждого вида деятельности есть свои мотивы, потребности, действия, задачи. Это обусловлено наличием у каждого вида деятельности своего предметного содержания [3, с. 18].

Существуют различные подходы к определению понятия «познавательная деятельность».

По мнению В.А. Беликова, познавательная деятельность заключается в том, что обучающийся под руководством своего учителя решает новые для себя практические и познавательные проблемы [1, с. 13]. Г.И. Щукиной трактует понятие «познавательная деятельность» как «познавательная деятельность самими учащимися» [4, с. 12]. В.А Беликов считает, что познавательная деятельность - это целенаправленное, сознательное выполнение физической или умственной работы, которая требуется ему для того, чтобы овладеть теми или иными навыками, знаниями, умениями [1, с. 14]. На основе изложенных подходов, можно прийти к выводу, что познавательная направленность в совокупности с имеющимся положительным опытом осуществления познавательной деятельности является причиной формирования желания непрерывно выполнять познавательную активность. Под влиянием обучения происходит постепенный переход от познания внешней стороны явлений к познанию их сущности, отражению в мышлении существенных свойств и признаков, что даст возможность делать первые обобщения, первые выводы, проводить первые аналогии, строить элементарные умозаключения. На этой основе у ребенка постепенно начинают формироваться научные понятия. Научное понятие - одна из форм отражения мира в мышлении, с помощью, которой познаётся сущность явлений, процессов, обобщаются их существенные стороны и признаки, что оказывает крайне важное значение на становление словесно-логического мышления. Овладение в процессе обучения системой научных понятий даёт возможность говорить о развитии у младших школьников основ понятийного или теорети- 
ческого мышления. Теоретическое мышление позволяет ученику решать задачи, ориентируясь не на внешние, наглядные признаки и связи объектов, а на внутренние существенные свойства и отношения [8, с. 35].

Хотя школьная успеваемость является результатом сложного взаимодействия между интеллектом и контекстными переменными, здоровье является жизненно важным сдерживающим фактором способности ребенка. Идея о том, что здоровые дети лучше обучаются, подтверждена эмпирически и хорошо принята (Basch, 2010), а многочисленные исследования подтвердили, что польза для здоровья связана с физической активностью, включая сердечно-сосудистую и мышечную пригодность, здоровье костей, психосоциальные результаты, а также когнитивное здоровье и здоровье мозга. (Strong et al., 2005). Взаимосвязь физической активности и физической подготовки с когнитивным здоровьем и здоровьем мозга, а также с успеваемостью. Учитывая, что мозг отвечает, как за умственные процессы, так и за физические действия человеческого тела, здоровье мозга важно на протяжении всей жизни. У взрослых здоровье мозга, представляющее отсутствие болезней и оптимальную структуру, и функцию, измеряется с точки зрения качества жизни и эффективного функционирования в повседневной деятельности. У детей здоровье мозга можно измерить с точки зрения успешного развития внимания, поведения при выполнении задания, памяти и успеваемости в образовательной среде.

В младших классах особое значение имеет готовность учеников применять приобретенные знания и познавательные учебные действия в решении реальных ситуаций. Новый ФГОС второго поколения акцентирует внимание на формировании у школьника личностных и творческих качеств, его духовно-нравственном формировании, и предлагает конкретные пути, обеспечивающие этот переход: изменение метода и средств обучения в разной деятельности. Это говорит о важности рассмотрения вопроса о современных и эффективных методах и средствах обучения.

Учителя должны стремиться к созданию позитивной учебной атмосферы, в которой основное внимание уделяется сотрудничеству. Сотрудничество, а не конкуренция. Учитель должен мотивировать учащихся делиться своими идеями и искать разъяснения, пока они не поймут это должным образом [7, с. 57]. Чтобы добиться такой учебной среды, учителям необходимо создать атмосферу взаимного доверия, поддержки, сочувствия и взаимоуважения. В такой среде учащиеся понимают, что во время обучения они могут иногда терпеть неудачу, но они должны собраться и продолжить свою борьбу, это отношение призывает их к активному участию в учебнометодическом процессе. Ученики не должны забывать то, о чем говорит доктор АРЈ Абдул Калам: «Неудача оз- начает первую попытку обучения».

Актуальной проблемой является выбор средств формирования познавательного компонента познавательных учебных действий в процессе образования. Дети, которые мотивированы на то, чтобы избежать неудачу ведут себя по-другому. Они осуществляют свою деятельность только для того, чтобы избежать разного рода неудач. Ребенок является неуверенным в себе. Он не верит в то, что может добиться успеха, опасается возникновения негативного мнения. При выполнении задач, где вероятность неудачи довольно высока, он переживает негативные эмоции, в результате чего пропадает удовлетворенность от осуществляемой деятельности. По этой причине зачастую он не может стать победителем, то есть является жизненным неудачником [9, с. 78].

Ребенок много времени посвящает тому, чтобы провести анализ осуществляемой деятельности, не отображая при этом свои переживания. Другими словами, его внутренние переживания нельзя понять по его внешнему виду, поведению [9, с. 13]. Учебная деятельность требует развития высших психических функций - произвольности, продуктивности и устойчивости всех познавательных процессов: внимания, памяти, воображения. Внимание, память, воображение младшего школьника уже приобретают самостоятельность - ребёнок научается владеть специальными действиями, которые дают возможность сосредоточиться на учебной деятельности, сохранить в памяти увиденное или услышанное, представить себе нечто, выходящее за рамки воспринятого раньше.

Чтобы учащиеся понимали новую информацию и идеи, им необходимо установить связи с существующими знаниями, чтобы они могли обрабатывать, а затем понимать новый материал. Это осмысление - это активный процесс, который может иметь место во время широкого спектра учебных мероприятий. Может быть в отличие от пассивного подхода к обучению, в котором учитель в первую очередь говорит «с учениками» и просто предполагает, что они будут понимать сказанное без необходимости проверять. Активное обучение требует от учащихся много думать и практиковать использование новых знаний и навыков для развития долгосрочного воспоминания и более глубокого понимания. Это глубокое понимание также позволит учащимся соединить различные идеи вместе и мыслить творчески. Активное обучение основано на теории обучения называется конструктивизмом, который подчеркивает тот факт, что учащиеся строят свое понимание. Жан Пиаже (1896-1980), психолог и основатель конструктивизма, исследовал познавательное развитие детей, отмечая, что их знания были индивидуальными и накапливались постепенно. В процессе осмысления дети заменяют или адаптируют свои существующие знания и понимание на более глубо- 
ком уровне понимания [10, с. 5].

Обучение происходит по мере того, как знания переходят от короткой к долговременной памяти и постепенно включается в более подробные и сложные ментальные модели, называемые схемами. Схемы можно рассматривать как категории, которые мы используем для классификации входящей информации (Wadsworth, 1996). Теория социального конструктивизма гласит, что обучение происходит прежде всего через социальное взаимодействие с другими людьми, например, учителем или сверстниками ученика. Один видный социальный конструктивист Лев Выготский (1896-1934) описал зону ближайшего развития (ЗПР). Это район где должна быть сосредоточена учебная деятельность, лежащая между тем, чего ученик может достичь самостоятельно и тем, что учащийся может достичь результатов под руководством специалиста.

Важно, чтобы учителя были хорошо осведомлены о теории, лежащей в основе активного обучения, чтобы избежать заблуждения, необходимо оценивать новые идеи, применять стратегии, которые полезны для их текущего контекста и цели.

Из всего вышеизложенного можно сделать вывод, что познавательный интерес проявляется в разных формax:

- в форме интеллектуальной активности. Ученик задает вопросы, которые несут в себе подлинный познавательный смысл. Например, вопросы, уточняющие что-то по теме или вопросы, открывающие перспективу дальнейшего познания. Так же ученик стремится активно участвовать в деятельности, обсуждать вопросы, поднимаемые на уроке, высказывать свою точку зрения, делиться знаниями, добытыми за пределами школы;

- в форме эмоционального проявления. В данном случае интерес ученика выдают: мимика, обостренное внимание, боязнь нарушить тишину, жесты, обмен впечатлениями с товарищем;

- в форме волевых проявлений, когда внимание ученика особенно сосредоточено, и он мало отвлекается на внешние раздражители, так как полностью поглощен заинтересовавшим его предметом, явлением. Так же показателем познавательного интереса школьника является особенность его поведения при возникновении затруднений.

Немаловажными являются факторы, которые побуждают учащихся к познавательной активности:

- творческий характер является стимулом к познанию, и определяется он со следующих позиций: творческой фантазией, уровнем мотивации, оригинальностью метода решения.
- исследовательский характер направлен на пробуждение в учениках творческого интереса, побуждает к самостоятельному поиску новых знаний.

Например, проведение учебного эксперимента, нетрадиционная форма занятия. Создание ситуаций интереса, занимательности, познавательной новизны, опоры на жизненный опыт помогают ребенку проявить активность в обучении. Учащиеся сами должны отстаивать свое мнение, принимать участие в дискуссиях, задавать вопросы своим одноклассникам и учителю, находить несколько решений задачи или же проблемы, ведь все это подталкивает ребенка размышлять, анализировать что способствует активности.

В качестве инновационного направления конструирования дидактического процесса в начальной школе в концепции необходимо использовать классификацию типов по характеру приоритетной деятельности, в которой участвует обучающийся на данном этапе обучения. Для успешной активизации познавательной деятельности необходимо в процессе обучения создавать условия для активизации познавательной деятельности, а также совершенствовать систему усвоения базовых знаний, умений и навыков, при этом необходимо соблюдать условия активизации познавательной деятельности:

- атмосфера доброжелательности и сотрудничества в классе;

- ситуация «успеха» для каждого учащегося;

- включение каждого учащегося в коллективные работы;

- использование нестандартных заданий при изучении нового или при повторении уже пройденного материала;

- учет индивидуальных особенностей учащихся;

- формирование у учащихся только положительных отношения и эмоций к обучению;

- максимальная опора на активную мыслительную деятельность учащихся.

При активизации познавательной деятельности педагог не только может, но и должен:

- учитывать интересы младших школьников и одновременно формировать мотивы их учения при организации познавательной деятельности;

- для повышения понимания предлагается включать младших школьников в решение проблемных ситуаций на уроке;

- использовать дидактические игры и дискуссии, различные интерактивные методы обучения.

Подводя итоги, следует отметить, что главной особенностью развития познавательных процессов детей младшего школьного возраста является переход психических познавательных процессов ребенка на более 
высокий уровень. Это, прежде всего, выражается в более произвольном характере протекания большинства психических процессов (восприятие, внимание, память, воображение), а также в формировании у ребенка абстрактно логических форм мышления и обучении его письменной речи. Создание ситуаций интереса, занимательности, познавательной новизны, опоры на жизнен- ный опыт помогают ребенку проявить активность в учении. Младшим школьникам необходимо самостоятельно отстаивать свое мнение, принимать участие в дискуссиях, задавать вопросы своим одноклассникам и учителю, находить несколько решений задачи или же проблемы, ведь все это подталкивает ребенка размышлять, анализировать, что способствует активности.

\section{ЛИТЕРАТУРА}

1. Беликов, В.А. Философия образования личности: Деятельностный аспект: монография / В.А. Беликов. - М.: Владос, 2013. - 357 с.

2. Леонтьев, А.Н. Деятельность. Сознание. Личность / А.Н. Леонтьев. -М.: Изд - во Смысл, Издательский центр «Академия», 2014. - 352с.

3. Мякишева Н.М. особенности познавательной деятельности младших школьников, или как современному школьнику сохранить познавательную потребность [Текст] // Начальная школа плюс до и после. - 2018. - №2. - С.18-24.

4. Щукина Г.И. Активизация познавательной деятельности учащихся в образовательном процессе. [Текст] - М.: Просвещение, 1979. 160 с

5. Шпаковская, Е. Поведенческие особенности людей, мотивированных на достижение успеха и избежание неудач. [Электронный ресурс] - режим доступа: http://www.komanda.ru/shpakovskaja/007a.html (Дата обращения 20.03.20)

6. Aubrey, K. and Riley, A. (2016). Understanding and using educational theories. London: SAGE Publications Ltd.

7. Cambridge Assessment International Education. (2019). Implementing the Curriculum with Cambridge: A Guide for School Leaders.

8. Coe, R., Aloisi, C., Higgins, S. and Elliot Major, L. (2014). What makes great teaching? Review of the underpinning research. Sutton

9. Johnston, A.M., Johnson, S.G., Koven, M.L., \& Keil, F.C. (2017). Little Bayesians or little Einsteins? Probability and explanatory virtue in children's inferences. Developmental Science, 20(6), 1-14

10. Horne, Z., \& Khemlani, S. (2018). Conceptual constraints on generating explanations. In C. Kalish, M. Rau, T. Rogers, \& J. Zhu (Eds.), Proceedings of the 40th Annual Conference of the Cognitive Science Society. Austin, TX: Cognitive Science Society.

11. Trust. Available at: www.suttontrust.com/wp-content/uploads/2014/10/What-makes-great-teaching-FINAL-4.11.14-1.pdf

12. Lieder, F., Griffiths, T.L., Huys, Q.J., \& Goodman, N.D. (2018). The anchoring bias reflects rational use of cognitive resources. Psychonomic Bulletin \& Review, 25(1), 322-349.

13. Education Endowment Foundation (EEF). (2019b). Metacognition and self-regulated learning. EEF. Available online at: https://educationendowmentfoundation. org.uk/public/files/Publications/Metacognition/EEF_Metacognition_and_selfregulated_learning.pdf

14. Mourshed, M., Krawitz, M. and Dorn, E. (2017). How to improve student educational outcomes, McKinsey \& Co. Available at: www.mckinsey.com/ /media/ McKinsey/Industries/Social\%20Sector/0ur\%20Insights/How\%20to\%20improve\%20student\%20educational\%20outcomes/How-to-improve-studenteducational-outcomes-New-insightsfrom-data-analytics.ashx

15. Tworek, C.M., \& Cimpian, A. (2016). Why do people tend to infer "ought" from "is"? The role of biases in explanation. Psychological Science, 27(8), 1109-1122

() Шадурко Олег Владимирович (9911151@gmail.com). 